УАK 005.521:32

ББК 66.06

DOI 10.22394/1682-2358-2017-3-108-117

A.A. Korobov, Doctor of Sciences (Politics), Professor of the Political Sciences Department, Povolzhsky Institute of Management named after P.A. Stolypin, Branch of the Russian Presidential Academy of National Economy and Public Administration

M.E. Shestakov, post-graduate student of the Political Sciences Department, Povolzbsky Institute of Management named after P.A. Stolypin, Branch of the Russian Presidential Academy of National Economy and Public Administration

\section{POSTER PROPAGANDA IN THE SYSTEM \\ OF MODERN \\ POLITICAL COMMUNICATION}

The poster form of political propaganda in the network telecommunications space is considered. Features of the use of propaganda posters in the modern system of political communications are analyzed, the dependence of the effectiveness of poster propaganda on the communication characteristics of the political space is revealed. The appropriateness of using the method of "targeted" poster propaganda under the conditions of informational oversaturation of the political and communication environment is substantiated.

Key words and word-combinations: political propaganda, propaganda poster, political communications, ideological influence.
A.A. КоробоВ, доктор политических наук, профессор кафедрьг политических наук ПоВолжского института упраһления имени П.А. Стольтина - филиала Российской академии народного хозяйства и государственной службь ири Президенте РФ (email: aakorobov@inbox.ru)

M.E. Шестаков, аспирант кафедро политических наук Поволжского института упрабления имени П.А. Стольтина - филиала Российской академии народного хозяйства и государственной службь при Президенте РФ (етаil: mesh91@yandex.ru)

\section{ПААКАТНАЯ ПРОПАГАНАА В СИСТЕМЕ СОВРЕМЕННЫХ ПОАИТИЧЕСКИХ КОММУНИКАЦИЙ}

\begin{abstract}
Аннотация. Рассматривается плакатная форма политической пропаганды в сетевом телекоммуникационном пространстве. Анализируются особенности использования пропагандистских плакатов в современной системе политических коммуникаций, выявляется зависимость эффективности плакатной пропаганды от коммуникационных характеристик политического пространства. Обосновывается приемлемость использования метода «адресной» плакатной пропаганды в условиях информационной перенасыщенности политико-коммуникационной среды.

Ключевые слова и словосочетания: политическая пропаганда, пропагандистский плакат, политические коммуникации, идеологическое воздействие.
\end{abstract}

$\Pi$ менаправленная деятельность по распространению среди населения определенных 
политических взглядов и мировоззренческих идей всегда привлекала к себе повышенное внимание научного и экспертного сообществ. Поскольку таким способом осуществляется сильное идейное воздействие на широкие слои населения, манипуяяџия социальным, политическим и шире - общественным, поведением народных масс, управление общественным сознанием, пропаганАа выступает в качестве одного из существеннейших факторов-регуляторов общественно-политического развития государства. Именно такое отношение к институту политической пропаганды обусловливает устойчивый интерес ко всестороннему изучению форм, методов, приемов и среАств современной пропаганды, определяет актуацьность исследования эволюции в контексте модернизации системы политических коммуникаций такого традиционного вида пропаганды, как пмакатная пропаганда.

Пропаганда является одним из наиболее постоянных политических процессов, протекающих в каждом без искцючения государстве мира. Термин «пропаганда» (от мат. «propagare» - распространять) имеет множество научных определений и трактовок, но в наиболее емком виде интерпретируется как «распространение и углубленное разъяснение каких- ибо идей, учений взглядов, знаний; идейное воздействие на широкие массы» [1, с. 413]. Субъектами политической пропаганды выступают органы власти, политические партии и Авижкения, общественные структуры, включая конфессиональные объединения, неформальные сетевые сообщества, отдельные граждане. И при устойчивом политическом режиме, и в период кардинальной трансформаџии политической системы общества пропаганда остается кцючевым элементом функционирования соџиально-политических институтов. Пропаганда всегда направлена на увеличение числа сторонников определенных политических идей. Как следствие, кажАый политический субъект пытается путем пропаганды решить свои задачи: офиџиальная власть - добиться мояльности со стороны своих граждан, получить общественную подАержку проводимой политики; оппозиция - настроить гражАан против государственной власти, отдельных ее представителей или в целом против всей существующей политической системы; политические партии, Авижения - привлечь внимание широкой общественности к какой-то соџиальной проблеме и заодно увеличить число своих сторонников, еАиномышиенников. К политической пропаганде часто прибегают и неполитические субъекты общественных отношений: церковь,

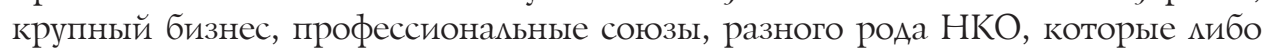
мично заинтересованы в доминировании среди своих адептов, потребителей товаров / услуг, членов определенной системы политических взглядов и идей, мибо выполняют чей-то заказ.

В зависимости от политической зрелости общества, от политико-правового режкима государства, от укоренившихся национально-культурных традиций пропаганда приобретает различные масштабы и формы. Принято считать, что самых больших масштабов политическая пропаганда Аостигает в тоталитарных государствах, где каждый индивид является мишь винтиком в сложной государственной системе, а наименьших - в странах с глубокими

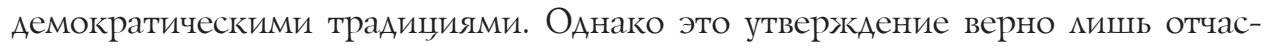


ти, поскольку масштаб и интенсивность процесса пропаганды одновременно задаются внешними и внутренними условиями сушествования политической системы общества. Именно поэтому даже при миберально-демократическом режкиме могут сложиться такие условия (внутренние или внешние - не суть важно), когда правящая элита вынуждена в интересах сохранения устойчивости государственного развития и обеспечения наџиональной безопасности сформировать такой мощный аппарат пропаганды, который ничем не будет уступать по кцючевым характеристикам анацогичному аппарату в тоталитарном государстве.

Политическая пропаганда использует размичные механизмы и технологии прямого или косвенного воздействия на население. Прямое воздействие осуществцяется средствами массовой коммуникации, прежде всего СМИ и информационно-аналитическими агентствами. Задачам пропаганды могут служить художественные и мультипликационные фильмы, поэзия, проза, научнопопуяярные и юмористические передачи на радио и телевидении, развлекательные шоу, осушествляющие косвенное, но не менее эффективное идейное воздействие на зрителей. Важкная роль в системе государственной пропаганды отводится школам, вузам, публичным библиотекам, спортивным клубам; а в системе негосударственной политической пропаганды - массовым публичным акциям, социальным сетям. Не вдаваясь в подробное описание огромного множества приемов и конкретных способов пропагандистского воздействия, сфокусируем в данной статье исследовательское внимание на одном виде помитической пропаганды - наглядной плакатной пропаганде.

Базовым инструментом плакатной пропаганды является плакат. В первоначацьной трактовке термин «плакат» означац «крупноформатное ( $и с-$ товое) издание (обычно в виде рисунка, изображения, сопровождаемого кратким текстом), выполняющее задачи наглядной агитаџии и пропаганды, информации, рекмамы, инструктажа ици обучения» [1, с. 390]. Позже, с развитием информационно-коммуникационных технологий и электронных изданий, плакат стал интерпретироваться более широко и вкцючать в себя рисунко-текстовое изображение на мюбом материально-техническом носителе информации. Пропагандистский плакат, в отличие от агитационного, обычно призывающего к конкретному Аействию, предназначен Аля формирования у мюдей, смотрящих на него, определенного (заранее заданного) отношения к тому или иному событию, факту, явлению. Это более Алительный проџесс, чем создание искусственной потребности что-то сАемать (например, проголосовать за конкретную политическую партию на выборах), но и отдача от плакатной пропаганды несопоставимо выше, чем от плакатной агитаџии. Последняя имеет вообще краткосрочный импульсный эффект: человек, подАавшись агитационному воздействию, например, отАал свой голос на выборах за нужного кандидата, поехал добровольцем работать на север или осваивать целину, принял участие в митинге или забастовке - и все. ГражАанин сделал то, что от него хотели. Агитационное воздействие прекратилось. В результате же плакатной пропаганды человек становится носителем определенной системы ценностей, которой он начинает непроизвольно 
руководствоваться в своей повседневной, профессиональной, общественнополитической жизни. Без каких-либо временных граниџ. Но чтобы эффект от пропагандистского воздействия не ослабевац, требуется непрерывность пропагандистского процесса. В нашем случае - непрерывность наглядной плакатной пропаганды.

Отметим, что постоянство (непрерывность) идеологического воздействия явцяется необходимым, но еще не достаточным условием Аця результативной плакатной пропаганды. Эффективность использования плаката в политической пропаганде скмадывается из двух компонент: непосредственного содержания плаката (его смысловой нагрузки и формы подачи) и пространственно-коммуникационной структуры распространения этого плаката.

Первая компонента эффективности определяется художественной формой и композиџией плаката. Именно композиџия пропагандистского плаката осуществляет эмоџионацьное воздействие на зрителя (оно существенно преобладает над рационацьным воздействием), изменяет его психологическое состояние, вызывает определенные чувства. С этой целью содержание плаката делают броским, понятным, быстро и удобно читаемым. Аیя кучшей выразительности главной идеи плаката используют широкую палитру красок, поскольку цвет наицучшим образом способствует появлению у зрителя чувств восторженности, радости, прекрасного и в равной степени негодования, змости, обиды и безразцичия. Необходимость правицьного составцения композиции обусловливается психологией зрительного восприятия плаката - зритель начинает рассматривать и, следовательно, воспринимать смысл плаката, как правицо, с центра композиции, затем его фокус внимания перемещается на остальные (периферийные) части композиции, а после - вновь возвращается в центр. Этот цики может повторяться несколько раз. Если композиция не учитывает этой последовательности в рассмотрении плаката индивидом, необходимого эмоџионального воздействия на зрителя может не произойти. Кроме того, пропагандистский плакат за счет художественной формы и композиции должен непременно обладать способностью привлекать внимание зрителей. В противном случае мюди увидят, но не обратят внимания на плакат и не подвергнутся эмоџионацьному воздействию. По мнению специалистов, плакат наицучшим образом привлекает внимание мюдей, если его композиџия построена на контрасте (цветовом или смысловом), обладает динамичностью (художник фиксирует момент начавшегося, но незавершенного Авижения) и ритмичностью [2] . Учет всех этих факторов в совокупности определяет, на наш взгляА, половину успеха использования плаката в политической пропаганде.

Вторая компонента эффективности применения плаката в пропагандистских целях связана со степенью соответствия системы пространственного распространения плаката уровню развития политических коммуникаций в государстве. При высокой степени этого соответствия пропагандистский плакат будет всегда находиться в поле зрения граждан и оказывать на них идейное воздействие. Низкая степень соответствия (ици вовсе его отсутствие) искцючает систематическое попадание плаката в поле зрения цюдей и резко 
снижает уровень эффективности плакатной пропаганды даже при высококачественном оформлении плаката с учетом всех перечисленных критериев его художественной композиции. Известно, что плакат вначале должен попасть

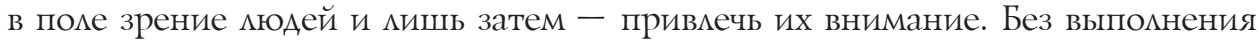
первого условия второе автоматически не выполняется. СлеАовательно, пространственное распространение плаката также является одним из важнейших элементов в процессе наглядной политической пропаганды.

Ставя вопрос о соответствии системы пространственного распространения плаката уровню развития политических коммуникаций, необходимо вначале опреАелить, что собой представляют политические коммуникации. Аанная научная категория весьма многогранна и имеет множество трактовок. В широком смысле слова под политическими коммуникациями понимается совокупность каналов связи, по которым циркулирует политическая информация. Но практически каждый исследователь, занимающийся проблемой политических коммуникаџий, старается Аать свое определение этому понятию. Например, М.С. Вершинин определяет политическую коммуникацию как «смысловой аспект взаимодействия субъектов политики путем обмена информацией в процессе борьбы за власть или ее осуществление...» [3, с. 51] ; С.Е. Гришин - как «систему, производящую, распредемяющую, обрабатывающую и обменивающую стандартизированную информацию, которая может повлиять (или влияет) на осушествление политической вмасти» [4, с. 15-16]. Поскомьку в настоящей публикации объектом исследования выступает плакатная пропаганда, а не политическая коммуникация, не станем акцентировать внимание на расхождениях в авторских интерпретациях понятия «политическая коммуникация», а попытаемся трактовать его в широком смысле слова.

От качественных и количественных характеристик политической коммуникации зависит как структура пространственного распространения плаката, так и его виА, формат. Пцакат может размешаться на страницах печатных многотиражных изданий: книг, журналов, газет, учебников или на страниџах стенгазеты; он может принять вид оформленного стенда в публичных местах, на стенах жилых зданий или промышиенных объектов, на интернет-порталах и web-сайтах и т.п. При этом сам плакат может иметь бумажный, цифровой (эмектронный) и иной формат. Гцавная задача в проџессе пространственного распространения пропагандистского плаката - он Аолжен непременно попадать в поле зрения граждан, причем максимально возможного количества мюдей, Аля воздействия на которых он и создавался. Поиск решения данной задачи как раз и определяется набором характеристик текущего состояния политических коммуникаций в стране. Остановимся на этом моменте более подробно.

Политические коммуникации представцяют собой систему, которая можкет быть открытой или закрытой - в зависимости от политического режима государства, жестко структурированной (иерархичной) или сетевой (одноуровневой) - в зависимости от Аоминирующей в обществе модели социальных взаимодействий, детерминированной или стохастической - в зависимости от степени контроля наА ней со стороны государства. Формы, разновидности и 
методы плакатной пропаганды напрямую зависят от трех ключевых факторов. Во-первых, от того, какие именно элементы политико-коммуникационной системы имеют возможность, обладают правом производить и распределять информацию (в нашем случае - пропагандистские плакаты). Во-вторых, какие канацы в сложившейся системе наиболее приспособлены Аля Аемонстрации пропагандистских плакатов аудитории. В-третьих, от условий производства и обращения в системе политической информаџии. Эти условия могут быть одинаковыми Аля всех видов политической информаџии, Аля всех субъектов политики или различными, причем в разной степени. Каждый из этих трех ключевых факторов, в свою очередь, зависит от характера существующей системы политических коммуникаций: ее открытости, детерминированности, иерархичности. В итоге вторая компонента эффективности плакатной пропаганды приобретает качество сложносоставной нелинейной функщии многих переменных.

ГАавной характерной чертой системы политических коммуникаций в первые шестнадцать мет XXI в. стала всеобъемлющая интернетизация - перехоА ключевых каналов передачи, хранения, обработки, распространения и обмена информации в интернет-среду, возникновение в данной среде новых независимых производителей и репродукторов информации и, как следствие, начало трансформации иерархической структуры политических коммуникаций в сетевую форму [5]. Этот процесс явмяется прямым результатом научнотехнического прогресса и естественной эволющии гражданского общества; он Аишь косвенно, частично подАается управлению и контролю со стороны органов государственной вмасти. Производством информации и ее распространением в Интернете занимаются как традиционные субъекты политических коммуникаций: средства массовой информаџии, пресс-служббы министерств, ведомств и отдельных офиџиальных миџ, PR- и PG-службы коммерческих и некоммерческих организаций, политических партий и движений, так и новые субъекты: блогеры, независимые аналитические интернет-агентства, частные мица - активные участники социальных сетей Livejournal, Facebook, Twitter и т.п. [6, с. 45-48].

В настоящее время социальные сети переполнены пропагандистскими плакатами неоднородной политической направленности. Существуют специализированные международные web-сайты, которые обслуживают популярные социальные сети, публикуя плакаты, представленные в формате политической карикатуры. К таким web-сайтам относятся, например, http://www. politicalcartoons.com и http://www.caglecartoons.com, целью которых явцяется объединение карикатурщиков всего мира дия презентации своих работ. Эти web-сайты не имеют российской версии, зато изображения плакатов Аоступны всем поисковым интернет-системам, в том числе и российским.

Отметим, что если на проџесс формирования сетевой формы политических коммуникаџий вцасть не может оказать существенного вцияния - это явцение носит, во многом, спонтанный характер, то в отношении самого процесса производства, воспроизводства, хранения и распространения информационных ресурсов такого не набцюдается. Государственная власть обладает 
всеми необходимыми правовыми и административно-техническими рычагами Аля регулирования циркумяџии политической, в том числе пропаганАистской, агитаџионной, рекмамной, информации в коммуникационном пространстве. При помощи разнообразных мегитимных инструментов вцасть может контролировать основные и периферийные информационные потоки, ослаблять или усиливать их, перенаправлять и блокировать эти потоки, миквидировать определенные информационные ресурсы. В зависимости от конкретных усмовий, которые создает государство Аля политико-коммуникационной среАЫ в определенный момент, плакатная пропаганда приобретает специфические черты: во-первых, ее основными субъектами (создатемями и распространителями плакатов) становятся мибо правительственные, проправительствен-

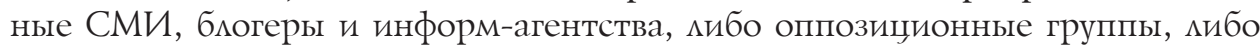
иностранные организации (возможно сочетание всех этих типов субъектов в разных пропорџиях); во-вторых, плакаты начинают преимущественно использоваться ици в цифровом формате, преимушественно, в интернетжурналах, интернет-газетах, соџиальных сетях, или традиционным способом: изготовляемые на материальных носителях плакаты размещаются в местах массового скопления мюдей. Следовательно, плакатная пропаганда вынуждена подстраиваться под создаваемые условия, выискивать в них оптимацьные Аля себя пути Аостижения цели.

Наглядным примером здесь может служить британский жкурнал «Тһе Economist», издательство которого использует обложки еженедельных номеров в формате пропагандистских плакатов. Редакция журнала освещает политические события, международные отношения и экономические новости с позиций классического миберацизма, что находит прямое отражение в содержании плакатов-обложек. В частности, стремясь очернить российскую политику на Бцижнем Востоке, особенно военные операции ВозАушнокосмических сил России в Сирийской Арабской Республике, на обложке электронной версии журнала «Тhe Economist» от 22 октября 2016 г., посвященного анализу этих вопросов, изображен демонический образ Президента России, в зрачках которого - два красных самолета, с заголовком «Путинизм» / «Putinism» - выражение, трактуемое в общем контексте журнаца как «идеология зАа» [7].

Эффективность плакатной пропаганды во многом зависит от коммуникационных характеристик самого политического пространства: от информационной насыщенности (чем она ниже, тем выше эффективность использования пропагандистских плакатов), от скорости обращения информации, от Аоступности информаџионных ресурсов и т.п. Повсеместное распространение Интернета в политическом пространстве преобладающего большинства стран мира привело к резкому, скачкообразному повышению уровня Аоступности граждан к политической информации и увеличению скорости ее получения [8]. Современное политическое пространство в информаџионно-коммуникационном плане перенасыщено общедоступной разноплановой соџиально и политически значимой информаџией. Она содержится и воспроизводится на интернет-порталах офиџиальной вцасти, политических, на- 
учных и общественных организациях, некоторых хозяйствующих субъектов, многочисленных массмедиа, независимых интернет-агентств, в соџиальных сетях, блогах, на частных сайтах граждан. По оџенке ряда экспертов, общий объем информаџии, находящейся в открытом Аоступе в глобальной телекоммуникационной сети, начиная с 2010 г., удваивается каждые два года - прежде всего, за счет автоматической генерации данных. В периоА с 2012 по 2020 г. ожидается увеличение общего объема информации в пятнадџать раз [9]. В обстановке информаџионной перенасыщенности политического пространства переА пользователями остро встает вопрос о вычменении из общего массива Аанных полезной и релевантной политической информаџии. Остальная информация исключительно психологически начинает восприниматься как информационный шум, помехи ици в кучшем скучае как информационный фон.

Как упоминалось, Аля идеологического воздействия пропагандистского плаката необходимо, чтобы зрители обращали внимание на плакат, проявцяли к нему интерес. Появление же такого интереса находится в обратно пропорџиональной зависимости от информационной насыщенности коммуникаџионной среды. При дефиџите политической информаџии зритель испытывает неудовлетворенную потребность в ней и поэтому «поглощает» мюбые информационные ресурсы, в том числе пропагандистские плакаты. В такой обстановке воздействие плакатов на сознание и, что более важно, на подсознание мюдей наиболее эффективно. Следовательно, масштабы плакатной пропаганды достигают огромных значений. По мере насыщения коммуникационной среды социально-политической информацией зритель начинает обращать внимание на более яркую, более интересную и более контрастную информацию, выдемяя ее («выхватывая») из общего информационного фона. В такой ситуации пропагандистские плакаты џемесообразно размешать только на тех интернет-ресурсах, которые являются наиболее посешаемыми в силу своей привлекательности дмя граждан. Так оно на практике и происходит. При Аальнейшем повышении степени насыщенности информацией, особенно в условиях информационной перенасыщенности, у Аюдей возникает потребность в «адресной» информации [10, с. 55], и производители, распространители пропагандистских плакатов попадают в зависимость от предпочтений аудитории. Они вынуждены адаптироваться к запросам аудитории, выделять из общего количества пользователей интернета определенные сегменты и уже только с учетом их специфических запросов и интересов продвигать свои плакаты.

В коммерческой рекламе и в маркетинге существует такой механизм выделения целевой аудитории и «обработки» ее рекламной продукцией, как таргетинг. Суть таргетинга состоит в выдемении из общего числа граждан той части (так называемой «целевой аудитории»), которая соответствует определенным, заранее заданным критериям, например определенному возрасту, местожительству, соџиальному статусу, интересам, предпочтениям, с последующим распространением рекламы конкретного товара или ускуги только среди этой части насемения. Высшей точки своего развития таргетинг достиг 
в условиях глобальной интернетизации общества, когда Аанный рекламный метод продвижения товаров и услуг прочно внедрияся в Интернет и стал выявцять целевые аудитории среди интернет-пользователей. Пцакатная пропаганда, осваивая интернет-среду в условиях информационной перенасыщенности, вынуждена быма пойти по этому же пути.

Технология таргетинга больше подходит дия рекламы, чем дия агитаџии и пропаганды. Таргетинг основывается на использовании предварительно собранных и обработанных данных о пользователях, поэтому он существенно повышает релевантность рекламной информации, улучшает ее восприятие и, как результат, - эффективность рекламной деятельности. Вместе с тем плакатная пропаганда можкет иметь цель воздействовать не на весь соџиум, а на отдельные его слои, группы, категории граждан, и тогда механизм таргетинга оказывается в наивысшей степени востребованным. У аАресной политической пропаганды имеется множество недостатков - фрагментарный охват насемения, необходимость в большой предварительной работе по тщательному сбору, систематизации и анализу данных о гражданах - пользователях Интернета, выявлению их интересов и потребностей, созданию художкественной композиции плаката, соответствующей целевой аудитории, существенные финансовые затраты. Но и преимущества налиџо: при сравнении адресной и классической плакатной пропаганды в Сети практическая отдача от первой многократно превышает отдачу от второй.

В итоге выявцяется, что плакатная пропаганда в системе современных помитических коммуникаций не снизила своего значения в качестве эффективного инструмента идеологического воздействия на население; уступила, но не сильно, место Аругим инновационным формам политической пропаганды. ОАнако кардинальная трансформация политико-коммуникационной среды, особенно в части ее телекоммуникационного сектора, потребоваца от плакатной пропаганды существенной модернизации, приведение приемов эмоционального воздействия плаката на зрителей в соответствие с уровнем развития политических интернет-технологий [11]. В государствах с развитым информационным обществом пропагандистские плакаты практически полностью преобразовались в цифровой формат и находят своего потребителя, целевую аудиторию через интернет-издания информационно-аналитических журналов, газет (ици интернет-версии печатной прессы), новостных ониайн-агентств, через блогосферу и многочисленные социальные сети. В государствах с низким уровнем развития информаџионных технологий (а следовательно, с низкими или умеренными уровнями информаџионной насыщенности, Аоступности информаџии, невысокой скоростью ее циркуляџии межАу политическими субъектами) плакатная пропаганда остается в прежнем виде, что, впрочем, полностью соответствует текущему состоянию политических коммуникаций в этих странах. По мере же проникновения Интернета (и связанных с ним новых технологических возможностей) во все сферы жизнедеятельности общества плакатная пропаганда не исчезает бесследно, а постепенно преобразуется в интернет-формат. 


\section{Библиографический список}

1. Словарь иностранных слов. 18-е изд. М., 1989.

2. Кудин П.А., Ломов Б.Ф., Митькин А.А. Психология восприятия и искусство плаката М., 1987.

3. Вершинин М.С. Политическая коммуникация в информационном обществе. СПб., 2001.

4. Гришин C.E. Политическая коммуникация в России в условиях информатизации государственного управления: автореф. дис. ... д-ра полит. наук. Саратов, 2012.

5. Коробов А.А., Мельникова Т.С., Митяева Н.В. Формирование общественной потребности в развитии систем электронного правительства и электронной демократии в современной России / под общ. ред. Т.С. Мельниковой. Саратов, 2016.

6. Акаев Д.В. Социально-политическая активность участников интернет-сообществ // Среднерусский вестник общественных наук. 2014. № 4. С. 45-48.

7. The Economist. URL: http://www.economist.com/printedition/2016-10-22

8. Бронников И.А. Политическая коммуникация и современность // Юридические исследования. 2013. № 4. С. 66-88.

9. Рост объема информации - реалии цифровой вселенной // Технологии и средства связи. 2013. № 1. C. 24-25. URL: http://www.tssonline.ru/articles2/bypub/tss-1-2013

10. Гришин C.E. Политическая коммуникация. Саратов, 2012.

11. Шестаков M.E. Роль информационно-коммуникационных технологий в эволюции плакатных форм политической пропаганды // Вестник Поволжского института управления. 2017. T. 17, № 1. C. 117-123. 